\title{
Tratamento de sementes de pau-brasil com fungicidas: efeito na incidência de fungos, germinação e transmissão de fungos pelas sementes
}

\author{
Tathiana Lisboa-Padulla ${ }^{1}$, Maria Heloisa Duarte de Moraes ${ }^{1}$, José Otávio Machado Menten ${ }^{1}$, Cláudio Barbedo ${ }^{2}$
}

${ }^{1}$ ESALQ/USP, C.P. 09, Piracicaba, SP, CEP 13418-900, e-mail talis padulla@gmail.com ${ }^{2}$ Instituto de Botânica,Caixa Postal 4005, CEP 01061970, São Paulo, SP.

Autor para correspondência: Tathiana Lisboa-Padulla

Data de chegada: 25/01/2007. Aceito para publicação em: 11/11/2008

\section{RESUMO}

Lisboa-Padulla, T.; Moraes, M.H.D.; Menten, J.O.M.; Barbedo, C.. Tratamento de sementes de pau-brasil com fungicidas: efeito na incidência de fungos, germinação e transmis são de fungos pelas sementes. Sum m a Phytopathologica, v.35, n.2, p.148-150, 2009

Os objetivos deste trabalho foram avaliar a eficiência de fungicidas no controle de fungos em sementes de pau-brasil, efeitos na germinação das sementes e a transmissibilidade destes fungos para plântulas. Os resultados mostraram que os fungos incidentes foram Pestalotiopsis sp., Cladosporium cladosporioides, Phoma sp. e Fusarium spp. e que todos os fungicidas (captam, benomil e carboxim+tiram) foram eficientes na redução dessa incidência, exceto para Fusarium spp. Em relação a porcentagem de plântulas normais, não houve diferença entre os tratamentos. Captam foi o mais eficiente, quando comparados os testes de sanidade e germinação, mas são necessários novos estudos para ajuste de dosagem, visando à redução na porcentagem de plântulas anormais e sementes mortas por provável fitotoxicidade do fungicida. Foi confirmada a transmissão de Pestalotiopsis sp. e Cladosporium cladosporioides, que causaram lesões nos cotilédones e hipocótilos das plântulas de pau-brasil.

Palavras-chave adicionais: tratamento, patogenicidade, Pestalotiopsis sp., Cladosporium cladosporioides.

\section{ABSTRACT}

Lisboa-Padulla, T.; Moraes, M.H.D.; Menten, J.O.M.; Barbedo, C.. Brazil-wood seeds treatment with fungicide: effect in fungi incidence, germination and transmission of fungi by seeds. Sum m a Phytopathologica, v.35, n.2, p.148-150, 2009

The objectives of this work were to evaluate the fungicide treatment in fungi control in brazil-wood seeds and with captan, benomyl and carboxin+thiram in brazilian-wood seeds, verifying the fungi control and to make the transmission test of fungi by seeds. The results showed that the fungi found were Pestalotiopsis sp., Cladosporium cladosporioides, Phoma sp. and Fusarium spp. All fungicides were efficient in the incidence of fungi, except for Fusarium spp. In relation to normal seedlings percentage there were no statistical difference between the treatments. The fungicide that show a higher efficiency, when compared the sanity and germination researches, however, the dose must be adjusted to decrease the percentage of abnormal seedlings and dead seeds by fungicide phytotoxicity. The transmission and of the fungi Pestalotiopsis sp. and Cladosporium cladosporioides, that caused lesions in cotyledons and hypocotylous of brazilian-wood seedlings had been confirmed.

Keywords: treatment, pathogenicity, Pestalotiopsis sp., Cladosporium cladosporioides.

São raros os estudos sobre qualidade sanitária de sementes de pau-brasil e poucos patógenos foram registrados causando danos à espécie. Poucos trabalhos relatam a presença de fungos associados diretamente às sementes, exceto os realizados por Lisboa et al. $(3,4,5)$, que efetuaram o levantamento de fungos em sementes de pau-brasil e detectaram Pestalotiopsis sp., Cladosporium cladosporioides, Phoma sp., Alternaria sp., Botryodiplodia sp., Drechslera sp., Curvularia sp., Aspergillus sp., Epicoccum sp. e Penicillium sp. Assim, é importante verificar possíveis prejuízos causados por esses fungos às sementes de pau-brasil, bem como mecanismos para seu controle. Neste trabalho, buscou-se avaliar a incidência dos fungos e possíveis danos desses sobre a germinação das sementes; a eficiência da utilização de fungicidas no controle da incidência de fungos e de seus efeitos e, também, a transmissão de fungos pelas sementes. Como não existe registro de fungicidas para essências florestais nativas, escolheram-se captam, benomil e carboxim+tiram, produtos recomendados para controle da maioria desses fungos em outras espécies vegetais. As doses utilizadas estão descritas na tabela 1. Após o tratamento, as sementes foram submetidas ao teste de sanidade pelo método do papel de filtro (2) e após 7 dias foi feita a identificação dos fungos associados. O teste de germinação foi feito pelo método do rolo de papel, conforme Brasil (1992) (2). A avaliação se deu após 7 e 15 dias, contando-se o número de plântulas normais ( $\mathrm{PN})$, plântulas anormais infeccionadas (PAI), plântulas anormais não-infeccionadas (PA) e sementes mortas (SM). O critério adotado para caracterizar uma plântula normal foi a presença de raiz, hipocótilo e primeiro par de folhas, sem que houvesse qualquer deformação existente. Foram consideradas plântulas anormais aquelas que apresentaram alguma deformação na raiz, hipocótilo, cotilédone, epicótilo e primeiro par de folhas, sendo que as infeccionadas puderam ser as sociadas a alguma espécie de fungo. O delineamento experimental, 
Tabela 1. Produtos e doses de fungicidas utilizados no tratamento de sementes de pau-brasil

\begin{tabular}{|c|c|c|c|c|}
\hline Produto Técnico & Produto Comercial & Dose do i.a.*/100kg de sementes & Dose do p.c. $* / 100 \mathrm{~kg}$ de sementes & Formulação* * \\
\hline Captam & Captan 750 TS & $150 \mathrm{~g}$ & $160 \mathrm{~g}$ & P.S. \\
\hline Benomil & Benlate 500 & $500 \mathrm{~g}$ & $200 \mathrm{~g}$ & S.C. \\
\hline Carboxim+Tiram & Vitavax + Thiram 200SC & $200 g+200 g$ & $450 \mathrm{~mL}$ & S.C. \\
\hline
\end{tabular}

*i.a.: ingrediente ativo; p.c.: produto comercial

**S.C.: Suspensão concentrada; P.S.: pó seco

Tabela 2. Incidência (\%) de fungos em sementes de pau-brasil, submetidas a tratamento com fungicidas

\begin{tabular}{llcc}
\hline Tratamento & Pestalotiopsis sp. & Cladospori umcladosporioides & Phoma sp. \\
\hline Testemunha & $38 \mathrm{a}^{*}$ & $66 \mathrm{a}$ & $9 \mathrm{a}$ \\
Captam & $0 \mathrm{~b}$ & $0 \mathrm{c}$ & $0 \mathrm{~b}$ \\
Benomil & $0 \mathrm{~b}$ & $19 \mathrm{~b}$ & $0 \mathrm{~b}$ \\
Carboxim+Tiram & $0 \mathrm{~b}$ & $24 \mathrm{~b}$ & 0 \\
CV $(\%)$ & 43,2 & 27,6 & $0 \mathrm{~b}$ \\
\hline
\end{tabular}

*Médias seguidas pela mesma letra, nas colunas, não diferem entre si pelo teste de Tukey a $5 \%$ de probabilidade.

Tabela 3. Porcentagem de Plântulas Normais (PN), Anormais Infeccionadas (PAI), Anormais Não-infeccionadas (PA) e Sementes Mortas (SM), obtidas de sementes de pau-brasil, submetidas a tratamento com fungicidas

\begin{tabular}{|c|c|c|c|c|}
\hline Tratamento & $\mathbf{P N}$ & PAI & PA & $\mathbf{S M}$ \\
\hline Testemunha & $81 a^{*}$ & $19 \mathrm{a}$ & $0 \mathrm{~b}$ & $0 \mathrm{~b}$ \\
\hline Captam & $79 \mathrm{a}$ & $0 \mathrm{~b}$ & $6 \mathrm{ab}$ & $15 \mathrm{a}$ \\
\hline Benomil & $75 \mathrm{a}$ & $0 \mathrm{~b}$ & $10 \mathrm{a}$ & $15 \mathrm{a}$ \\
\hline Carboxim+Tiram & $72 \mathrm{a}$ & $0 \mathrm{~b}$ & $12 \mathrm{a}$ & $16 \mathrm{a}$ \\
\hline CV $(\%)$ & 5,6 & 36,6 & 61,0 & 58,0 \\
\hline
\end{tabular}

*Médias seguidas pela mesma letra, nas colunas, não diferem entre si pelo teste de Tukey a $5 \%$ de probabilidade.

para os testes de sanidade e germinação, foi inteiramente casualizado, com 5 repetições de 20 sementes. Os resultados foram submetidos a análise de variância e as médias comparadas pelo teste de Tukey $(0,05)$. Os dados foram transformados segundo arco seno da raiz quadrada de $(\mathrm{x} / 100)$, onde $\mathrm{x}$ é o valor percentual obtido.

Para o teste de transmissão, plântulas normais e anormais obtidas no teste de germinação de sementes não tratadas (testemunha) foram transplantadas para vaso com solo esterilizado, mantidas em casa de vegetação e observadas quanto ao surgimento de lesões diariamente. Ao surgirem as lesões, os fragmentos de tecidos das plântulas com sintomas foram colocados em câmara úmida para a identificação dos fungos associados.

Os resultados apresentados na Tabela 2 evidenciam a presença dos fungos Pestalotiopsis sp., Cladosporium cladosporioides, Phoma sp. e Fusarium spp. as sociados às sementes. Os fungicidas reduziram a incidência dos fungos, com destaque para captam que, praticamente erradicou os mesmos das sementes, exceto para Fusarium spp. Conforme os dados da Tabela 3, a porcentagem de plântulas normais não diferiu es tatistic amente entre os tratamentos. A porcentagem de plântulas anormais infeccionadas foi maior nas sementes não-tratadas, diferindo dos demais tratamentos. Estas plântulas apresentavam fungos associadas a elas, o que, provavelmente, contribuiu para a sua anormalidade. Nas sementes tratadas, as que germinaram não originaram plantas anormais infeccionadas, provavelmente, pelo fato dos fungicidas terem diminuído consideravelmente a incidência dos fungos nas mesmas. Já a porcentagem de plântulas anormais não-infeccionadas foi maior em sementes tratadas. Estas plântulas apresentavam algumas deformações, como cotilédone deformado e raiz diminuta ou retorcida, sem que houvesse algum fungo as sociado às deformaçõ es, evidenciando efeito fitotóxico dos fungicidas. O efeito fitotóxico dos fungicidas ficou mais evidente quando se observou que a porcentagem de sementes mortas foi maior nos tratamentos do que na testemunha (que foi zero). Assim, novos estudos com dosagens menores de fungicidas para o tratamento das sementes devem ser feitos, pois, a redução de doses pode diminuir o efeito de plântulas anormais não-infeccionadas e de sementes mortas e, não nec essariamente, deixaria de controlar a incidência dos fungos nas sementes.

Em relação ao teste de transmissão, $81 \%$ das plântulas transplantadas foram consideradas normais e $19 \%$ anormais infeccionadas. Das normais, $85 \%$ originaram mudas sadias e $15 \%$ morreram, sendo que não apresentaram lesões que pudessem ser associadas aos fungos. Todas as plântulas anormais infeccionadas morreram e, nas lesões originadas, foi possível isolar e identificar os fungos Pestalotiopsis sp. em 99\% delas, e Cladosporium cladosporioides, em 1\%.C. cladosporioides causou lesões no cotilédone, de formato irregular e coloração escura. Pestalotiopsis sp. foi identificado em lesões de cotilédone, de formato irregular, com coloração escura, onde foi possível observar a presença de cirros pretos do fungo e, em plântulas tombadas, com lesão no hipocótilo de formato circular, pequeno e escuro, com cirros evidentes. Em plântulas com lesões no cotilédone, o primeiro par de folhas não se desenvolveu, enquanto que, nas lesões no hipocótilo, próximas ao cotilédone, o primeiro par de folhas tinha se des envolvido. Com esses resultados, evidencia-se a transmissão de Pestalotiopsis sp. e C. cladosporioides pelas sementes de pau-brasil, uma vez que esta caracteriza-se pelo estabelecimento do patógeno transportado pela semente, proporcionand o uma infecção bem sucedida, dando origem a uma planta doente onde, o único meio de inoculação foi através da associação do patógeno com a semente (7). 


\section{AGRADECIMENTOS}

Os autores agradecem à FAPESP pela aprovação do Projeto Temático Caesalpinia echinata Lam. (pau-brasil): da semente à madeira, um modelo para estudos de plantas arbóreas tropicais brasileiras, que originou os estudos relatados, além do Dr. Cláudio José Barbedo pelas contribuições fornecidas.

\section{REFERÊNCIAS BIBLIOGRÁFICAS}

1. Barnett, H.L.; Hunter, B.B.; Illustrated genera of imperfect fungi. St. Paul: The American Phytopathological Society, 1998. $218 \mathrm{p}$.

2. Brasil. Ministério da Agricultura e da Reforma Agrária. Regras para análise de sementes. Brasília: SNDA/DNDV/CLAV, 1992.
3. Lisbôa, T.; Moraes, M.H.D.; Pascholati, S.F. Incidência de fungos em sementes de Caesalpinia echinata (pau-brasil) coletadas em diferentes estádios de desenvolvimento. Informativo ABRATES, Curitiba, v.13, n.3, p. 377, 2003 a.

4. Lisbôa, T.; Moraes, M.H.D.; Pascholati, S.F. Qualidade sanitária de sementes de Caesalpinia echinata (pau-brasil) no momento da coleta e após armazenamento. Informativo ABRATES, Curitiba, v.13, n.3, p. 376, 2003 b.

5. Lisbôa, T.; Moraes, M.H.D.; Menten, J.O.M. Sanidade e potencial germinativo de sementes de Caesalpinia echinata, Lam (paubrasil) coletadas no campus da ESALQ/USP, em Piracicaba. In: SIMPÓSIO BRASILEIRO DE PATOLOGIA DE SEMENTES, 8, 2004: João Pessoa. Palestras e Resumos: João Pessoa, 2004. $182 \mathrm{p}$.

6. Menten, J.O.M.; Bueno, J.T. Transmissão de patógenos pelas sementes. In: Soave, J.; Wetzel, M.M.V. da Silva (Eds.). Patologia de sementes. Campinas: Fundação Cargill,1987. cap.7, p. 164-189. 